Chi, Tailan. (2002) Rethinking Rouse and Daellenbach's Rethinking: Isolating Versus Testing for Sources of Sustainable Competitive Advantage. Strategic Management Journal, 23, 957-962. Publisher's Official Version: http://dx.doi.org/10.1002/smj.255/

Open Access Version: http://kuscholarworks.ku.edu/dspace/

[This document contains the author's accepted manuscript. For the publisher's version, see the link in the header of this document.]

\title{
Rethinking Rouse and Daellenbach's Rethinking: Isolating Versus Testing for Sources of Sustainable Competitive Advantage
}

\author{
By Edward Levitas and Tailan Chi \\ The University of Wisconsin-Milwaukee and The University of Kansas
}

Paper citation:

Chi, Tailan. (2002) Rethinking Rouse and Daellenbach's Rethinking: Isolating Versus Testing for Sources of Sustainable Competitive Advantage. Strategic Management Journal, 23, 957-962.

\begin{abstract}
:
In a recent paper, Rouse and Daellenbach (1999) provide a five-step methodological approach which they feel will cure alleged inadequacies in empirical resource-based research. We suggest, however, that their methodology can provide only a useful aid for expanding our understanding of potential sustainable competitive advantages but will not allow researchers to effectively verify those hypothesized advantages. Specifically, we argue that Rouse and Daellenbach's methodology is plagued by three major shortcomings: 1) it confuses the important distinction between knowing-how and knowing-what; 2 ) it fails to recognize the importance of observable variables in verifying the sources of sustainable competitive advantage; and 3 ) it calls for sampling on the dependent variable.
\end{abstract}




\title{
Rethinking Rouse and Daellenbach's Rethinking:
}

Isolating Versus Testing for Sources of Sustainable Competitive Advantage

\author{
Edward Levitas \\ University of Wisconsin-Milwaukee \\ School of Business Administration \\ 3202 N. Maryland Avenue \\ Milwaukee, WI 53211 \\ Ph: (414) 229-6825 \\ Fx: (414) 229-6957 \\ levitas@uwm.edu \\ Tailan Chi* \\ University of Illinois at Urbana-Champaign \\ Department of Business Administration \\ 350 Wohlers Hall, MC-706 \\ 1206 S 6th Street \\ Champaign, IL 61820 \\ Ph: (217) 333-9003 \\ Fx: (217) 244-7969 \\ tchi@uiuc.edu \\ *Corresponding author.
}

This paper has benefited from discussions with Vince Barker.

Accepted for publication in Strategic Management Journal, 23, pp. 957-962, 2002. 


\title{
Rethinking Rouse and Daellenbach’s Rethinking: \\ Isolating Versus Testing for Sources of Sustainable Competitive Advantage
}

\begin{abstract}
In a recent paper, Rouse and Daellenbach (1999) provide a five-step methodological approach which they feel will cure alleged inadequacies in empirical resource-based research. We suggest, however, that their methodology can provide only a useful aid for expanding our understanding of potential sustainable competitive advantages but will not allow researchers to effectively verify those hypothesized advantages. Specifically, we argue that Rouse and Daellenbach's methodology is plagued by three major shortcomings: 1) it confuses the important distinction between knowing-how and knowing-what; 2) it fails to recognize the importance of observable variables in verifying the sources of sustainable competitive advantage; and 3) it calls for sampling on the dependent variable.
\end{abstract}


Chi, Tailan. (2002) Rethinking Rouse and Daellenbach's Rethinking: Isolating Versus Testing for Sources of Sustainable Competitive Advantage. Strategic Management Journal, 23, 957-962. Publisher's Official Version: http://dx.doi.org/10.1002/smj.255/

Open Access Version: http://kuscholarworks.ku.edu/dspace/

In a recent issue of the Strategic Management Journal, Rouse and Daellenbach (1999) (RD) present a provocative critique of empirical methods used to test the resource-based view of the firm (RBV). Although many observers have questioned researchers' abilities to empirically validate the RBV, some scholars have pointed to recent progress made in this regard (Wernerfelt, 1995). RD, however, question not only the progress of current empirical works focussing on the RBV but also the efficacy of the methods that extant researchers have typically used — that is, large-sample studies based on secondary sources of data. They suggest that RBV researchers should shift their emphasis from "coarse-gained” methods of empirical analysis to more balanced approaches which include "intrusive” (page 490) methods such as ethnography and field work. To demonstrate, RD point to Penrose’s (1960) “inside” research of the Hercules Powder Company as an example where intrusive methods disclosed distinctiveness drivers that would go unnoticed in more traditional testing. Indeed, Penrose’s (1960) single-firm case study provides more richness of detail than can be expected from most large, multiple firm examinations. Yet, we suggest that studies such as Penrose’s (1960) or others emphasizing RD’s proposed methodology can provide a first step toward understanding sustainable competitive advantages, but will not allow researchers to effectively verify the effects of those hypothesized advantages. Indeed, Penrose explicitly recognizes this in her Hercules Powder study. When pondering how to assess the rate of firm growth (i.e., a central topic in her Theory of the Growth of the Firm), Penrose (1960: 20-21; emphasis added) admits "here, of course, we can only speculate, draw inferences from the course of events, and attempt to interpret statements made by the officials of the firm.” In a similar vein, we suggest that the use of RD's prescriptions can certainly allow researchers to develop a larger “catalogue” of potential sources of sustainable competitive 
Chi, Tailan. (2002) Rethinking Rouse and Daellenbach's Rethinking: Isolating Versus Testing for Sources of Sustainable Competitive Advantage. Strategic Management Journal, 23, 957-962. Publisher's Official Version: http://dx.doi.org/10.1002/smj.255/

Open Access Version: http://kuscholarworks.ku.edu/dspace/

advantage $^{1}$ but will not allow researchers to conclusively verify the distinctiveness or sustainability of those potential sources. Specifically, RD’s methodology is plagued by three major shortcomings: 1) it confuses the important distinction between knowing-how and knowing-what (e.g., Kogut \& Zander, 1992); 2) it fails to recognize the value of observable variables in verifying the existence of unobservable sources of sustainable competitive advantage (Godfrey \& Hill, 1995); and 3) it calls for sampling on the dependent variable (e.g., Makadok \& Walker, 2000).

\section{MAIN ARGUMENTS OF RD}

The principal contention that RD make in their article is that "[s]tudies of competitive advantage using the RBV require a different approach” than the dominant "large-sample, crosssectional analyses” that rely on secondary sources of data (page 488). They provide three key arguments to support their views about the inadequacy of the prevailing empirical methods. First, "since only firms with unique resources and competencies are assumed to have the potential for competitive advantages, the use of large-sample, cross-sectional analyses is unlikely to be able to disentangle the variety of effects associated with time, industry, environment, strategy, and the resource/capability of interest.” This argument has been used to criticize crosssectional analysis in general (e.g., Bowen \& Wiersema, 1999), but RD’s emphasis is perhaps that large sample sizes are not suitable for pinpointing idiosyncrasies that provide a firm with true competitive advantage. Second, data gathered from secondary sources (e.g., annual reports, industry association newsletters, and trade journals) are readily available to all competitors and therefore cannot be measures of unique and valuable competencies. The reason for this is that because "new technologies diffuse rapidly...competitors are likely to react quickly to

\footnotetext{
${ }^{1}$ Intimate company exploration may alert researchers to potential distinctiveness drivers that would otherwise escape their attention. We thank two anonymous reviewers for pointing this out as well as for suggesting the term
} 
Chi, Tailan. (2002) Rethinking Rouse and Daellenbach's Rethinking: Isolating Versus Testing for Sources of Sustainable Competitive Advantage. Strategic Management Journal, 23, 957-962. Publisher's Official Version: http://dx.doi.org/10.1002/smj.255/

Open Access Version: http://kuscholarworks.ku.edu/dspace/

actions/resources/competencies discernable from secondary sources (page 488).” Third, intrusive methods provide the key to uncovering sustainable advantages because as "sustainable advantages are organizational in origin, tacit, highly inimitable, socially complex, probably synergistic, embedded in process, and often driven by culture, there can be no other way to obtain the data of interest (page 489).” RD focus on pinpointing idiosyncrasies that give a firm unique strength. Because of the causally ambiguous nature of these idiosyncrasies, only intrusive work can accomplish this goal.

Based on these arguments, RD suggest that RBV researchers shift emphasis from the prevailing “coarse-gained” research methods to more intrusive methods (e.g., fieldwork, ethnographies) “which [take] the researcher into the organization (pages 489-490).” They recommend the following empirical methodology as a way to address the perceived inadequacies of the currently dominant research methods: 1) identify the industry to be studied and associated performance measures; 2) cluster the firms in the identified industry into strategic groups; 3) identify a performance hierarchy within each group; 4) classify firms within each strategic group into high, moderate, and low performers; 5) omit the moderate performers "to allow a more stark comparison between high and low level performers (page 489);” and 6) study the reason for performance differences through intrusive fieldwork.

\section{RD’S IMPLICIT ASSUMPTIONS AND THEIR SHORTCOMINGS}

\section{Know-What Versus Know-How}

As noted, one argument that RD give for the inadequacy of large-sample studies using publicly accessible secondary sources of data is that any competencies discernible from such sources will invoke rapid retaliatory responses by competitors. This argument rests on the assumption that data which reveal the presence and strength of some valuable resource are 
Chi, Tailan. (2002) Rethinking Rouse and Daellenbach's Rethinking: Isolating Versus Testing for Sources of Sustainable Competitive Advantage. Strategic Management Journal, 23, 957-962. Publisher's Official Version: http://dx.doi.org/10.1002/smj.255/

Open Access Version: http://kuscholarworks.ku.edu/dspace/

generally sufficient to allow imitation or some other rapid, retaliatory response by competitors (page 488). We feel that this presumption is overly simplistic. For example, publicly available patent data show the number of patents granted to various firms in a given year. By comparing the number of patents or citations to patents (i.e., the number of times a patent is cited by subsequent patents) received by each firm in a given industry with the intensity of their R\&D expenditures, one can obtain a reasonable indicator of the firms’ relative competence in performing R\&D (e.g., Griliches, 1990; Trajtenberg, 1990). This information, however, in no way enables patenting firms’ competitors to duplicate or match the underlying inventive capability. This is evidenced by Intel's dominance of the personal computer microprocessor market. As another example, competitors could easily discern from marketing campaigns and consumer satisfaction surveys that the high speed at which Toyota and Honda are able to introduce new models into worldwide automobile markets gives these companies some advantage over less efficient competitors. Yet, although they could try to accelerate their innovation processes, competitors still face much difficulty in imitating Honda and Toyota’s engineering quality and efficiency due to such things as time compression diseconomies and asset mass efficiencies (Dierickx and Cool, 1989). ${ }^{2}$

The inability to replicate that which is "publicly available” rests in the distinction between know-what (i.e., information that is easily exchanged among parties) and know-how (i.e., team-based, taken-for-granted capabilities that are experientially acquired, and thus, costly to transfer) (Kogut \& Zander, 1992; Teece, Pisano \& Shuen, 1997). Thus, members of a distinctive firm may know how to position resources in a superior manner and may be able to signal the possession of these capabilities via secondary data, but may be unable to easily

\footnotetext{
${ }^{2}$ Time compression diseconomies refer to the inability to recreate in a short period of time that which required a much longer period to develop. Asset mass efficiencies refer to achievement-induced momentum.
} 
Chi, Tailan. (2002) Rethinking Rouse and Daellenbach's Rethinking: Isolating Versus Testing for Sources of Sustainable Competitive Advantage. Strategic Management Journal, 23, 957-962. Publisher's Official Version: http://dx.doi.org/10.1002/smj.255/

Open Access Version: http://kuscholarworks.ku.edu/dspace/

articulate/transfer these capabilities to parties outside of firm boundaries. Indeed, RD even state "many elements of superior performance are predicted to be tacit in nature, which means that members of the organization cannot easily articulate what they are (page 490).” Yet, curiously, their arguments imply that this tacitness is rapidly dissipated by some form of public disclosure. Other researchers, however, have relied on patterns of superiority revealed in secondary data to identify truly distinctive firms (e.g., Henderson \& Cockburn, 1994; Makadok \& Walker, 2000). These researchers recognize that patterns of distinction in performing certain tasks can indicate a firm's possession of valuable and relatively unique resources/capabilities but do not reveal the key to imitating unique strategies. We will return to this point in the next section. ${ }^{3}$

Equally as striking is RD's belief that researchers will be capable of understanding the tacit elements of competence. RD emphasize the need to disentangle and understand the actual determinants of distinctiveness. This is certainly a desirable goal. Yet, it is not evident to us why researchers would expect to understand and subsequently articulate via published journal articles that which managers/employees find difficult to articulate. In fact, if a firm's distinctive capabilities could be fully understood and articulated by outsiders (e.g., a researcher or group of researchers), it must also be feasible for a single insider or group of insiders to fully grasp these capabilities and duplicate them elsewhere. As Peteraf (1993) argues through her example of the Nobel prize winning scientist, such ease of transfer prohibits these capabilities from forming the basis of a competitive advantage. If these capabilities reside completely in an individual/group, that individual/group could erode the advantage to the firm by exiting the firm and recreating the

\footnotetext{
${ }^{3}$ Additionally, although RD suggest that publicly disclosed data "could not form the basis of a sustainable competitive advantage" (page 488), we wonder if such disclosures could actually be used to strengthen some competitive advantages. A growing body of literature has discussed how distinctive firms use new product offerings, press releases, conferences, and other vehicles as a signal of the intention to use superior competitive positions to dissuade competitor advances (e.g., Balachander \& Srinivasan, 1994; Milgrom \& Roberts, 1986; Porter, 1980). This willingness and desire (as opposed to fear) of dominant firms to reveal their superiority via secondary data seems to support the belief that the existence of competitive advantages can be culled from secondary data.
} 
Chi, Tailan. (2002) Rethinking Rouse and Daellenbach's Rethinking: Isolating Versus Testing for Sources of Sustainable Competitive Advantage. Strategic Management Journal, 23, 957-962. Publisher's Official Version: http://dx.doi.org/10.1002/smj.255/

Open Access Version: http://kuscholarworks.ku.edu/dspace/

firm's strategy via the establishment of a new firm, or by using this threat to command higher wages from the firm (Dierickx and Cool, 1989; Lipmann \& Rumelt, 1982).

Furthermore, it is not evident that anything short of this complete understanding will allow intrusive researchers to achieve the goal of isolating sources of competitive advantage. For, without complete comprehension, it seems highly unlikely that a researcher could truly isolate those which grant distinctiveness from those that are simply necessarily for average performance. Distinctiveness is generally determined by a network of evolving and complex resource/capability interactions (Black \& Boal, 1994; Lipmann \& Rumelt, 1982) which will make the possibility of “disentanglement” highly unlikely. By way of illustration, we can explore the increasingly popular capability of learning. Research has suggested that learning is determined by the integration of technology absorption abilities (Cohen \& Levinthal, 1990), cohesiveness among employees (Woodman, Sawyer \& Griffin, 1993), proximity to sources of external knowledge (Jaffe, Tratjenberg \& Henderson, 1993), experience (Stuart \& Podolny, 1996), access to complementary assets such as cash and laboratory equipment (Teece et al., 1997), as well as a multitude of other individual, organizational, and environmental factors (e.g., Crossan, Lane, \& White, 1999; Levinthal \& March, 1993). In order to isolate the factors that give a firm superior learning capabilities, one needs to understand all interaction points that exist among various resources/capabilities, unravel those that are not possessed by competitors, and finally identify those unique attributes that are actually valuable. Furthermore, as RD (page 489) make it amply clear, it is often how the components are put together in a business process, rather than the presence of certain component resources/capabilities, that give a firm its competitive advantage. So, true isolation of the firm's sources of competitive advantage would require that one understand the firm's proprietary organizational know-how. Without this comprehension, an 
Chi, Tailan. (2002) Rethinking Rouse and Daellenbach's Rethinking: Isolating Versus Testing for Sources of Sustainable Competitive Advantage. Strategic Management Journal, 23, 957-962. Publisher's Official Version: http://dx.doi.org/10.1002/smj.255/

Open Access Version: http://kuscholarworks.ku.edu/dspace/

intrusive researcher risks identifying "sources of sustainable advantage" that are not valuable or unique, or worse, are competitively inferior to those of competitors (i.e., this complexity might lead researchers to identify the "wrong” resources/capabilities). There is, therefore, a fundamental paradox in the pursuit of isolating sources of competitive advantage: reliable isolation is unattainable without full comprehension, but full comprehension will enable outsiders to replicate what makes the firm unique (e.g. Arrow, 1962).

The Role of Observable Outcomes in Understanding and Testing for Sources of Competitive

\section{Advantage}

In order to verify that certain resources/capabilities actually determine sustainable competitive advantages, therefore, we must choose another course. Often, one must validate a theory empirically through verification of its predictions without having to operationalize all of its key constructs. As pointed out by Godfrey and Hill (1995: 530; emphasis in the original), "ultimately, the RBV will stand or fall not on the basis of whether its key constructs can be verified, but upon whether its predictions correspond to reality observed for populations of firms." The essence of their argument is that difficulties in operationalizing the constructs of the RBV such as culture, reputation, or learning need not impinge on the testing of that theory. Indeed, similar to the testing of transaction cost economics or agency theory, where researchers have yet to operationalize the costs of cheating or shirking but have still provided robust tests of the theories, RBV researchers can examine the outcomes of the processes predicted by the RBV. In other words, researchers can test for the existence of such "unobservables” by examining their observable outcomes (Godfrey \& Hill, 1995). The works of Henderson and Cockburn (1994), Robins and Wiersema (1995), Markides and Williamson (1996), and Makadok and Walker (2000) are four such (but not the only) studies that provide empirical verification of the RBV's 
predictions without operationalizing all its key theoretical constructs. As noted, RD (page 489) focus on intrusive techniques because "there can be no other way to obtain the data of interest." Godfrey and Hill, however, argue that the “data of interest” may not be obtainable but that this inability need not impinge on the testing of the RBV.

Admittedly, the use of “observable outcomes” in the research design does not allow one to obtain the richness of detail that might ordinarily be desired. And, the fact that the variables included in the empirical model may fail to represent all unique firm effects could cause other undesirable consequences. ${ }^{4}$ RD's desire to make such richness more commonplace is, therefore, laudable. However, sacrificing the validity of conclusions for the sake of "richness" will not further, and may even detract from, our understanding of sources of competitive advantage. Sampling on the Dependent Variable

RD’s methodology faces another major problem: sampling on the dependent variable. ${ }^{5}$ To illustrate, it is useful to examine RD’s linen supply company (pages 490-491). The linen supply company was operating at a cost disadvantage in a cost driven industry and, in an effort to increase efficiency, had considered outsourcing its delivery operations. Using intrusive techniques, a consultant had realized that the company’s delivery people had developed intimate relationships with its buyers. Accordingly, s/he advised the company to continue operating its own delivery routes. Imagine if a researcher were to use RD’s methodology to examine this linen supply industry. Consistent with RD, if the researcher finds that only the industry leaders (the top performing cluster in RD’s framework) and not the bottom-tier firms (the lowperforming cluster in RD’s framework) possess the above-noted delivery relationship, the

\footnotetext{
${ }^{4}$ For example, researchers may be forced to insert firm-specific fixed effects to control for such "ignorance"-induced omissions (Kennedy, 1996: 222).
} 
Chi, Tailan. (2002) Rethinking Rouse and Daellenbach's Rethinking: Isolating Versus Testing for Sources of Sustainable Competitive Advantage. Strategic Management Journal, 23, 957-962. Publisher's Official Version: http://dx.doi.org/10.1002/smj.255/

Open Access Version: http://kuscholarworks.ku.edu/dspace/

researcher might conclude that the delivery relationship formed some source of unique advantage. However, another possibility which cannot be ruled out using RD’s framework emerges. What if moderate performing firms (i.e., those that were eliminated from further analysis) also possessed this characteristic. If that were the case and the researcher could verify this using a sample representative of the linen supply industry, the researcher might believe that intimate delivery relationships were merely necessary for earning normal returns in that industry (i.e., all average and above-average performing firms in the linen supply industry would possess this relationship). In this case, delivery relationships would merely be required for adequate performance. The use of RD’s methodology precludes us from testing this "hypothesis”. 6

\section{CONCLUSIONS}

We suggest that RD’s proposals can provide a useful aid in identifying a larger catalogue of potential sources of sustainable advantage. These proposals, however, will not allow researchers to create defendable conclusions about these resources. The key to empirically advancing the RBV is simple: one must empirically verify patterns in populations of firms to corroborate researchers conjectures about the existence and sustainability of alleged advantages (e.g., Godfrey \& Hill, 1995). After all, the key to the RBV is sustainability. As RD suggest, the RBV's central focus is on factors which, in a sustained manner, favorably differentiate one firm from its competitors. To reasonably conclude that a firm's resource base has such an effect, one needs to confirm that resources are both cross-sectionally (to gauge distinctiveness) and

\footnotetext{
${ }^{5}$ This refers to the case where the selection criterion used to select the sample of firms to be used in subsequent analyses is based on values of the dependent variable. RD's methodology leads to such sampling as only high and low (but not moderate) performers are contained in the sample.

${ }^{6}$ In addition, what distinguishes the top-performers from the average firms could be their degree of efficiency in carrying out certain business functions such as linen delivery. The difference in efficiency in turn could result from a variety of factors such as incentive mechanisms and screening and training of truck drivers. Hence, in order to isolate the "true" sources of competitive advantage, one needs to identify not only the key potential benefit from a specific business practice but also the cost-effective process for carrying out the practice. This inevitably gets the
} 
longitudinally (to gauge sustainability) predictive of superior performance. More commonly used methods of data collection and analysis may lack the richness of detail desired by RBV researchers. Yet, these methods are indispensable in that they enable researchers to develop samples of firms that are representative of a larger population under study, and enable researchers to create a longitudinal series of data in order to verify perceptions of sustainable advantage. The issue for the RBV, therefore, is not to de-emphasize such methods, but rather to strive for creativity in operationalizing constructs (whether they are "key" constructs or hypothesized outcomes of "key” construct procession) and empirically measuring theorized outcomes.

researcher into the business of uncovering proprietary business know-how, which, as we suggested, tends to be tacit in nature and thus difficult to observe and costly to transfer. 
Chi, Tailan. (2002) Rethinking Rouse and Daellenbach's Rethinking: Isolating Versus Testing for Sources of Sustainable Competitive Advantage. Strategic Management Journal, 23, 957-962. Publisher's Official Version: http://dx.doi.org/10.1002/smj.255/

Open Access Version: http://kuscholarworks.ku.edu/dspace/

\section{References}

Arrow, Kenneth J. 1962. Economic welfare and the allocation of resources for invention. In National Bureau of Economic Research, editor, The Rate and Direction of Inventive Activity, 609-625, Princeton, NJ: Princeton University Press.

Balachander, S. and K. Srinivasan. 1994. Selection of product line qualities and prices to signal competitive advantage. Management Science 40: 824-841.

Black, J. A. and K. B. Boal. 1994. Strategic resources: traits, configurations, and paths to sustainable competitive advantage Strategic Management Journal 15 (Special Issue): 131148.

Bowen, H. P. and M. F. Wiersema. 1999. Matching method to paradigm in strategy research, Limitations of cross-sectional analysis and some methodological alternatives Strategic Management Journal 20: 625-636.

Cohen, W. M. and D. A. Levinthal. 1990. Absorptive capacity: A new perspective on learning and innovation, Administrative Science Quarterly 35: 128-152.

Crossan, M. M., H. W. Lane, and R. E. White. 1999. An organizational learning framework: From intuition to institution. Academy of Management Review 24: 522-537

Dierickx, I. and K. Cool. 1989. Asset stock accumulation and sustainability of competitive advantage, Management Science 35: 1504-1511.

Godfrey, P. C. and C. W. L. Hill. 1995. The problem of unobservables in strategic management research, Strategic Management Journal 16: 519-533.

Griliches, Z. 1990. Patent statistics as economic indicators: A survey, Journal of Economic Literature 28: 1661-1707.

Henderson, R. and I. Cockburn. 1994. Measuring competence? Exploring firm effects in pharmaceutical research, Strategic Management Journal 15 (Special Issue): 29-44.

Jaffe, A. B., M. Trajtenberg, and R. Henderson. 1993. Geographic localization of knowledge spillovers as evidenced by patent citations, Quarterly Journal of Economics 76: 984-1001.

Kennedy, P. 1996. A Guide to Econometrics. $3^{\text {rd }}$ ed. Cambridge, MA: MIT Press.

Kogut, B. and U. Zander. 1992. Knowledge of the firm, combinative capabilities, and the replication of technology, Organization Science 3: 383-397.

Levinthal, D. A. and J. G. March. 1993. The myopia of learning. Strategic Management Journal 14 (Special Issue): 95-112.

Lipmann, S. \& R. Rumelt. 1982. Uncertain imitability: An analysis of interfirm differences in efficiency under competition. Bell Journal of Economics 13: 418-438.

Makadok, R. and G. Walker. 2000. Identifying a distinctive competence: Forecasting ability in the money fund industry, Strategic Management Journal 21: 853-864. 
Markides, C.C. and P. J. Williamson. 1994. Related diversification, core competencies and corporate performance, Strategic Management Journal 15 (Special Issue): 149-166.

Milgrom, P. and J. Roberts. 1986. Price and advertising signals of quality, Journal of Political Economy 94, 796-821.

Penrose, E. T. 1959. The Theory of the Growth of the Firm. New York: Wiley.

Penrose, E. T. 1960. The growth of the firm. Business History Review 34: 1-23.

Peteraf, M. A. 1993. The cornerstones of competitive advantage: A resource-based view. Strategic Management Journal 14: 179-191.

Porter, M. E. 1980. Competitive Strategy. New York: Free Press.

Robins, J. and M. F Wiersema. 1995. A resource-based approach to the multibusiness firm: Empirical analysis of portfolio interrelationships and corporate financial performance. Strategic Management Journal 16: 277-300.

Rouse, M. J. and U. S. Daellenbach. 1999. Rethinking research methods for the resource-based perspective, Isolating sources of sustainable competitive advantage, Strategic Management Journal 20: 487-494.

Stuart. T. E. and J. M. Podolny. 1996. Local search and the evolution of technological capabilities, Strategic Management Journal 17(Special Issue): 21-38.

Teece, D. J., G. Pisano, and A. Shuen. 1997. Dynamic capabilities and strategic management, Strategic Management Journal 18: 509-533.

Trajtenberg, M. 1990. A penny for your quotes, patent citations and the value of innovations, Rand Journal of Economics 21: 172-187.

Wernerfelt, B. 1995. The resource-based view of the firm: Ten years after, Strategic Management Journal 16: 171-174.

Woodman, R. W., J. E. Sawyer and R. W. Griffin. 1993. Toward a theory of organizational creativity, Academy of Management Review 18: 293-321. 